\title{
Pharmacological enhancement of motor function recovery in patients with acute ischaemic stroke: a trial of fluoxetine
}

\begin{abstract}
Background: Hemiparesis and hemiplegia are sequelae of stroke and constitute major disability. Studies have shown heightened brain plasticity in the first one month post stroke with positive influence on motor recovery. We set out to identify a role for early commencement for the drug fluoxetine in enhancing motor recovery in patients with acute ischaemic stroke.

Methods: This was a single-blind, randomized, controlled trial carried out at the University of Uyo Teaching Hospital, Uyo. Participants were patients older than 18 years of age with clinical and neuroimaging evidence of stroke, hemiparetic with FMMS $<55$, NIHSS $<16$ and enrolled after giving informed consent. Block randomisation was done, with patients assigned to two groups in a 1:1 ratio; fluoxetine $20 \mathrm{mg}$ once a day + hospital stroke protocol or hospital stroke protocol alone for one month starting as soon as patients were enrolled. Outcome measures were the FMMS and the Barthel index at enrolment and exit.

Results: Thirty eight participants were analysed using intention to treat principle. The mean change in FMMS showed a positive trend in the fluoxetine group. Furthermore, the mean Barthel index at exit in the fluoxetine group was significantly higher than the control group $\mathrm{p}<0.03$
\end{abstract}

Conclusion: Fluoxetine, if started in the acute phase of ischaemic stroke may improve functional status. It also shows a positive trend towards enhancing motor recovery.
Volume 9 Issue I - 2019

\author{
Franklin O Dike,' Bertha C Ekeh,' Abayomi \\ S Ogun, ${ }^{2}$ Udeme E Ekrikpo,' Paul Walshak,' \\ Adesola A Ogunniyi ${ }^{3}$ \\ 'Department of Internal Medicine, University of Uyo teaching \\ hospital Uyo, Nigeria \\ 2Department of Internal medicine, Lagos State University \\ Teaching hospital, Nigeria \\ ${ }^{3}$ Department of Internal medicine, University College Hospital \\ Ibadan, Nigeria
}

\section{Correspondence: Dr. Franklin Dike, Neurology Unit, Department of Internal Medicine, University of Uyo teaching hospital Uyo,Akwa Ibom state, Nigeria, Tel +234703303865I,} Email frankincense4m@yahoo.com

Received: November 13,2018 | Published: February 22, 2019

Keywords: Stroke, ischaemic stroke, acute stroke, motor recovery, fluoxetine, Fugl meyer

\section{Introduction}

Current data places stroke mortality in Nigeria at an all high of 244,800 people every year ${ }^{1}$ with 30 -day case fatality rates varying between $35 \%-77 \% .^{2,3}$ This is high when compared with stroke mortality of 130000 /year in the USA and 50000/year in the UK. ${ }^{4}$ About $3.4-5.9 \%$ of all stroke patients receive thrombolysis in the USA $^{5}$ while the rate of thrombolysis in the UK was $9.6 \%$ in $2015 .{ }^{6}$ Poverty, lack of education and late presentations as well as a poor healthcare system are a few of the reasons advanced for inability to keep up with current standards of care in developing countries. ${ }^{7,8}$

The endpoint of stroke is either mortality or survival. Of the survivors, there will be varying degrees of morbidity with neurological deficits while few will have full recovery. These deficits including hemiparesis often lead to permanent impairment, disabilities and reduced quality of life. Some persons adapt well to severe impairment whereas some others will be severely disabled. The functional status is assessed by measures of dependency like the Barthel index, and the modified Rankin scale. The Fugl Meyer Motor Score (FMMS) on the other hand is an adequate measure of residual motor function and recovery. Spontaneous functional brain recovery therefore leads to an improvement of the Barthel index and FMMS. This concept of spontaneous brain recovery after stroke occurs as a result of increased neural plasticity. ${ }^{9}$ Therefore, the prospect of modulating this neural plasticity using drugs with the aim of enhancing the rate and amount of recovery has generated much interest. ${ }^{10,11}$ An emphasis in clinical trials have been placed on drugs that increase the amounts of neurotransmitters in the brain including amphetamines, monoaminergic drugs, levodopa, methylphenidate and antidepressants such as the tricyclic anti-depressants and the selective serotonin re-uptake inhibitors (SSRI). ${ }^{12}$ Dextro-amphetamine was shown to enhance recovery after brain injury in animal studies when combined with lesion-specific motor training after experimental brain injury but insufficient evidence has been found in human studies. ${ }^{13,14}$ Levodopa on the other hand has been found to produce significant improvement in motor function in a human clinical trial when compared to placebo using the Rivermead Motor Assessment as outcome measure..$^{15}$ Fluoxetine, a SSRI was also demonstrated to produce significant change in motor function compared to placebo in the FLAME trial. ${ }^{16}$ The goal of this trial was to evaluate the benefits of early commencement of fluoxetine in acute ischaemic stroke with respect to enhancement of motor function recovery in survivors.

\section{Methods}

\section{Trial design}

This was a single-blind randomized controlled trial that compared motor recovery between 2 groups of stroke patients: those on fluoxetine $20 \mathrm{mg}$ daily + standard therapy; and the control group who received standard therapy only. Sixty participants were enrolled in a 1:1 ratio and motor function and recovery were assessed using the FMMS, the Barthel index and the modified Rankin score.

\section{Participants}

The sample size was calculated using the formula for comparison of two means and each group had 30 participants. All the participants had acute supratentorial ischaemic stroke and presented within 14 days of ictus. Their ages were between $18-85$ years. Enrolled were 
those with admission NIHSS $<16$ with moderate to severe disability as dictated by an FMMS of $<55$. All the participants gave consent or assent by proxy. Comatose patients, those with severe stroke and comorbidities and those with neuroimaging evidence of intracerebral haemorrhage were excluded. The study took place from January 2015 - May 2016 at University of Uyo Teaching hospital. Block randomization was used in the assignment of study participants. Permuted blocks of six (6) for two groups were drawn up. A random selection of possibilities was done using a list of random numbers generated with STATA 12. Allocation concealment was done using sequentially numbered envelopes. Randomisation and allocation concealment were done by the study statistician while the major investigators were responsible for the outcome assessments at baseline and exit. The investigators assistant did the allocation assignments and the dispensing of fluoxetine. All participants gave consent or assent by proxy, and Ethical approval was granted by the institutional H-REC and registered with the Pan African Clinical Trials Registry (PACTR 201412000967245).

\section{Outcomes}

The NIHSS was used to assess stroke severity at entry. The Barthel index, the Fugl Meyer Motor scale and the modified Rankin scale were administered to all participants at entry day 0 and at exit on day 30. Primary outcome was the change in the FMMS between entry and exit. Secondary endpoints included the changes in the Barthel index, and the modified Rankin score at entry and exit. Participants were also under observation for the adverse effects of fluoxetine. The trial was designed to have a greater than $90 \%$ power to detect a $25 \%$ change in the FMMS within the 30 days of treatment.

\section{Statistical methods}

Continuous variables were reported as means and SD. Categorical variables were reported as percentages. Baseline characteristics were compared by Student's t-test/ Mann Whitney u test or $\pi 2$ test as indicated. Statistical significance was defined as $p<0.05$. Pairwise correlation was used to furnish probabilities for multiple comparisons. Data was analysed using intention to treat analysis. Other variables were then generated using STATA 12.

\section{Results}

A total of 60 patients were studied, 30 each in the Fluxetine (Group A)or Control group (Group B). The mean age of participants in the fluoxetine group was $59 \pm 11$ years compared to $62 \pm 9$ years in the standard management only group. About $55.2 \%$ of participants in group A were males, compared to $44.8 \%$ in the group B. Mean blood pressures in both groups were similar, with similar frequency of hypertension; $80 \%$ in group A and $83.3 \%$ in group B. Group A had a higher percentage of participants with left hemiparesis, with $56.7 \%$, compared to $43.3 \%$ in group B. The mean NIHSS severity scores were similar, 11.1 and 11.5 in groups A and B respectively. The MADRS scores also did not show any difference in both groups with a mean of

10.36 and 10.66 in groups A and B respectively. More participants in group B were in the low socioeconomic class (62.7\%) compared to $50 \%$ in group A, but this was not statistically significant (Table 1). Participants in group B also had higher mean baseline Barthel index scores, but this was also not statistically significant with a p-value of 0.43. Baseline FMMS scores were similar for both groups (Table 2).
Table I Comparison of sociodemographic factor of both groups

\begin{tabular}{llll}
\hline & $\begin{array}{l}\text { GROUP A } \\
(\mathbf{n = 3 0 )}\end{array}$ & $\begin{array}{l}\text { GROUP B } \\
(\mathbf{n = 3 0 )}\end{array}$ & P-value \\
\hline $\begin{array}{l}\text { Age in years } \\
\text { (mean, SD) }\end{array}$ & $59( \pm 11)$ & $62( \pm 9)$ & 0.25 \\
$\begin{array}{l}\text { Sex } \\
\text { Female (freq, \%) }\end{array}$ & $14(45.2 \%)$ & $17(54.8 \%)$ & 0.43 \\
Male (freq, \%) & $16(55.2 \%)$ & $13(44.8 \%)$ & \\
SES & $15(50 \%)$ & $19(62.7 \%)$ & \\
low (freq, \%) & $15(50 \%)$ & $11(36.7 \%)$ & \\
Middle (freq, \%) & 0 & 0 & 0.30 \\
High (freq, \%) & 0 &
\end{tabular}

*SES = Socio-economic status ST - Standard management; GroupA=fluoxetine + standard therapy; Group B= standard therapy only

Table 2 Risk factor characteristics of participants in both groups at baseline.

\begin{tabular}{llll}
\hline & $\begin{array}{l}\text { Group A } \\
(\mathbf{n = 3 0 )}\end{array}$ & $\begin{array}{l}\text { Group B } \\
(\mathbf{n}=\mathbf{3 0})\end{array}$ & p-value \\
\hline Obesity (freq, \%) & $9(30.0)$ & $14(46.6 \%)$ & 0.18 \\
Hypertension (freq, \%) & $24(80 \%)$ & $25(83.3 \%)$ & 0.74 \\
SBP 0 (mean, SD) & $166( \pm 34)$ & $173( \pm 24)$ & \\
DBP 0 (mean, SD) & $93( \pm 20)$ & $100( \pm 28)$ & 0.84 \\
DM (freq, \%) & $13(43.3 \%)$ & $10(33.3 \%)$ & 0.43 \\
\hline
\end{tabular}

SBP, systolic blood pressure; DBP, diastolic blood pressure; DM, diabetes mellitus.

Differences in both treatment groups were examined using Student's $t$ test. Group

Mean Glasgow Coma Score was similar in both groups $12 \pm 2$, and durations of stroke prior to enrolment was not significantly different between both groups with a p-value of 0.53 (Table 3 ).

Table 3 Stroke characteristics and measures of severity/disability at enrolment, day 0

\begin{tabular}{llll}
\hline & $\begin{array}{l}\text { GROUP } \\
\mathbf{A}(\mathbf{n}=\mathbf{3 0})\end{array}$ & $\begin{array}{l}\text { GROUP } \\
\mathbf{B}(\mathbf{n}=\mathbf{3 0})\end{array}$ & P value \\
\hline $\begin{array}{l}\text { Paretic side } \\
\text { (Right) (Freq, \%) }\end{array}$ & $\begin{array}{l}13(43.3 \%) \\
\text { ( Left) (Freq, \%) }\end{array}$ & $17(56.7 \%)$ & 0.30 \\
$\begin{array}{l}\text { Duration of stroke in days } \\
\text { (mean, SD) }\end{array}$ & $3( \pm 3)$ & $3( \pm 3)$ & 0.60 \\
$\begin{array}{l}\text { Glasgow coma score(mean, } \\
\text { SD) }\end{array}$ & $12( \pm 2)$ & $12( \pm 2)$ & 0.53 \\
NIHSS 0(mean, SD) & $11( \pm 4)$ & $12( \pm 4)$ & 0.61 \\
$\begin{array}{lll}\text { MADRS 0(mean, SD) } \\
\text { Barthel index 0(mean, SD) }\end{array}$ & $11( \pm 17)$ & $15( \pm 20)$ & 0.43 \\
$\begin{array}{l}\text { modified Rankin } \\
\text { Score(mean, SD) }\end{array}$ & $4( \pm 1)$ & $4( \pm 1)$ & 0.33 \\
FMMS 0(mean, SD) & $24( \pm 20)$ & $21( \pm 17)$ & 0.63 \\
$\begin{array}{l}\text { Upper limb(mean, SD) } \\
\text { Lower limb(mean, SD) }\end{array}$ & $15( \pm 14)$ & $13( \pm 13)$ & 0.73 \\
\hline
\end{tabular}

In the primary analysis the mean change in FMMS was marginally higher in the treatment group, $28 \pm 20$ points compared to $23 \pm 23$ points in group B (Table 4). However, this difference did not attain statistical significance, with a p-value of 0.27 . 
Mean Barthel index at day 30 was higher in the fluoxetine group achieving statistical significance with a p value of 0.03 (Table 5). Seventy per cent of participants in group A achieved independence, defined as a score greater than 75 on the Barthel index at day 30 compared to $53 \%$ in group B (Figure 1).

\section{Mortality and survival}

The study recorded a case fatality of fifteen within the follow up period, seven $(23 \%)$ in the intervention group and eight $(27 \%)$ in the standard therapy group. Deaths were ascribed to complications of the stroke and poor nursing care at home. Aspiration pneumonitis with respiratory failure, sepsis from pressure sores and suspected pulmonary embolism were the suspected causes of death. However, eight (8) of these deaths occurred after discharge from the hospital. No confirmatory autopsy was done on any of the cases.

Survival analysis done using a Kaplan-Meier method showed a trend with marginally higher chance of survival in the fluoxetine and standard management group compared to group B at 14 days, though this was no longer present at 30 days (Figure 2). Incidence rate of death stood at 0.008 in group A and 0.011 in group B. However, log rank test for comparison was not significant at $\mathrm{p}$-value of 0.74 . Male: female ratio survival function combined was also not statistically different, $\mathrm{p}=0.83$.

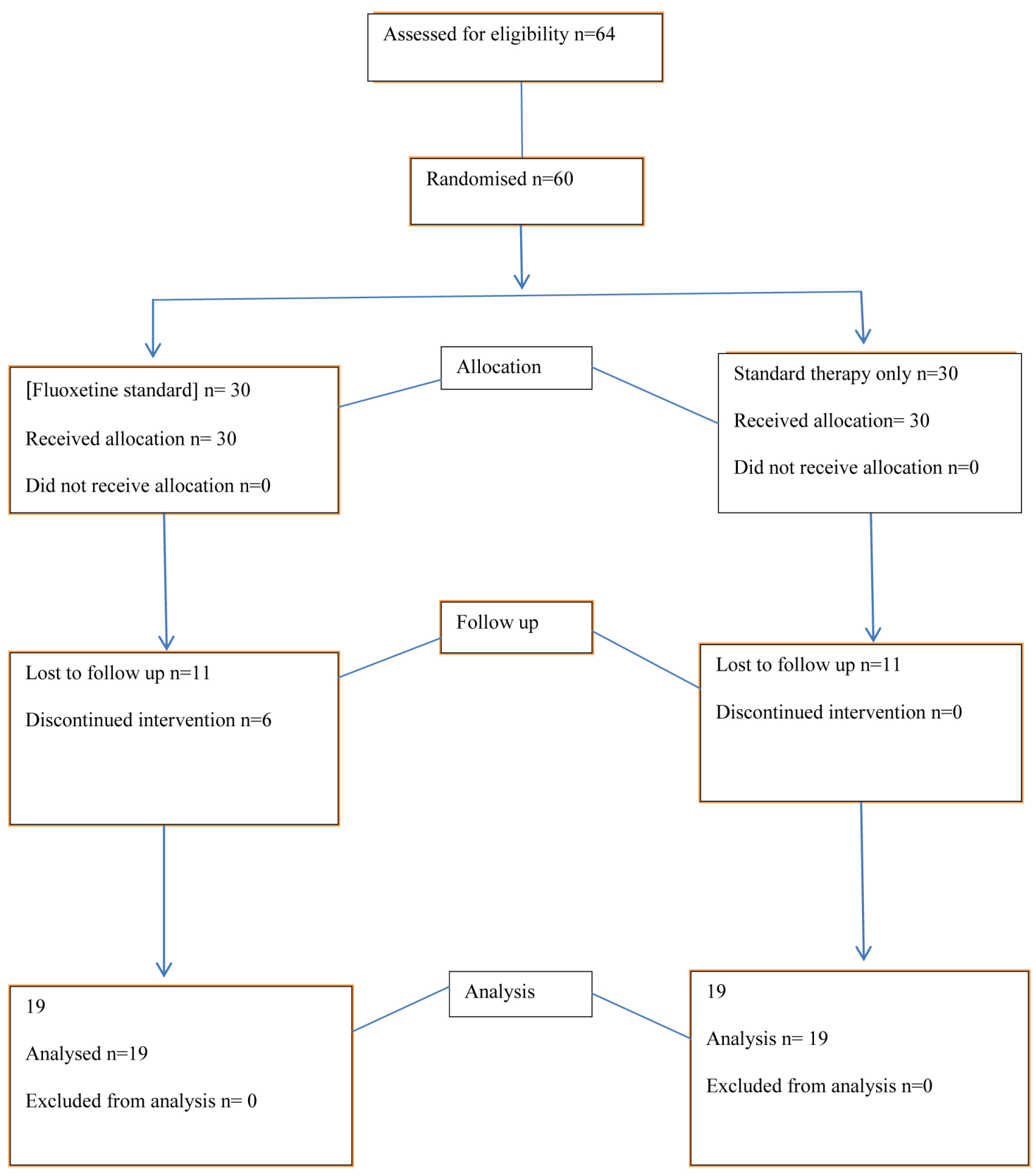

Figure I Flow diagram. 
Table 4 Comparing the FMMS in both groups at day 30

\begin{tabular}{|c|c|c|c|}
\hline \multicolumn{2}{|l|}{ DAY 30 GROUP A(n=19) } & \multirow[t]{2}{*}{ GROUP B(n=19) } & \multirow[t]{2}{*}{ P value } \\
\hline FMMS total & & & \\
\hline mean(SD) & $55( \pm 26)$ & $46( \pm 25)$ & 0.32 \\
\hline median(IQR) & $52(31-83)$ & $53(19-62)$ & \\
\hline \multirow[t]{2}{*}{ Upper limb(mean, SD) } & $36( \pm 21)$ & $27( \pm 19)$ & 0.22 \\
\hline & 33 & 33 & \\
\hline \multirow[t]{2}{*}{ Lower limb(mean, SD) } & $21( \pm 8)$ & $19( \pm 9)$ & 0.36 \\
\hline & 18 & 17 & \\
\hline $\begin{array}{l}\text { Change in FMMS from } \\
\text { day } 0-30 \text { (mean, SD) }\end{array}$ & $28( \pm 20)$ & $23( \pm 23)$ & 0.27 \\
\hline
\end{tabular}

The difference in the mean changes in the total FMMS in both groups was tested for significance using the Mann-Whitney $U$ test. Non-linearity of the data was confirmed by the Shapiro-Wilk test. Group A=fluoxetine + standard therapy; Group B= standard therapy only; $n=19$

Table 5 Comparison of the mean NIHSS score, mRS and Barthel Index (day 30)

\begin{tabular}{llll}
\hline & $\begin{array}{l}\text { GROUP- } \\
\mathbf{A}(\mathbf{n}=\mathbf{1 9})\end{array}$ & $\begin{array}{l}\text { GROUP- } \\
\mathbf{B}(\mathbf{n}=\mathbf{1 9})\end{array}$ & P value \\
$\begin{array}{l}\text { NIHSS at day } 30 \\
\text { (mean/SD) }\end{array}$ & $7( \pm 3)$ & $8( \pm 3)$ & 0.12 \\
mRS at day 30 & $3( \pm 1)$ & $3( \pm 1)$ & 0.35 \\
mean(SD) & $3(2-4)$ & $3(3-4)$ & \\
median(IQR) & & & \\
Barthel index at day 30 & & $49( \pm 30)$ & 0.03 \\
mean(SD) & $71( \pm 33)$ & $50(25-75)$ & \\
median(IQR) & $100(35-100)$ &
\end{tabular}

The level of significance of the difference between the means of both treatment groups was estimated using the Mann-Whitney $U$ test. Group A=fluoxetine + standard therapy; Group B= standard therapy only; $n=19$

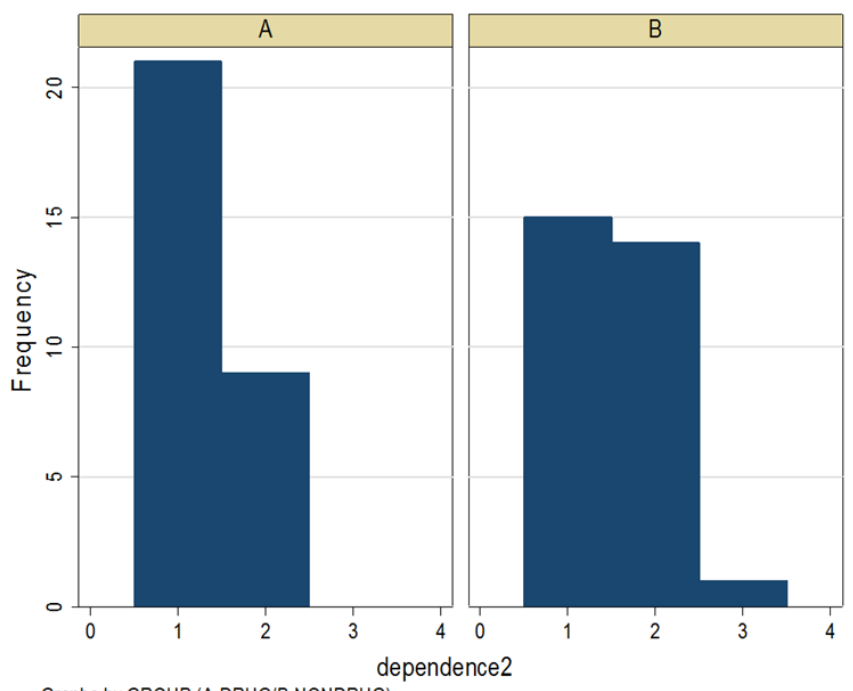

Graphs by GROUP (A-DRUG/B-NONDRUG)

Figure 2 Graphs showing distribution of levels of independence achieved in both groups, defined using day 30 Barthel index scores. Group A is the fluoxetine group, and Group B the standard management only group. Outcomes were categorized into Independent (Barthel index $\geq 75$ ), and Dependent (Barthel index $<75$ ).
Cox proportional hazard ratio for age was $1.6 \%$ (1.016), implying that for every increase in age there was a $1.6 \%$ increased risk of death at 30 days. However this was not statistically significant, $\mathrm{p}=0.53$.

\section{Adverse events}

The most common adverse events reported were excessive lethargy and drowsiness by two (6\%) participants in the fluoxetine group while three $(10 \%)$ participants complained of nausea. Overall the drug was well tolerated.

\section{Discussion}

This study shows a trend for benefit in functional status of the patients although motor function recovery using FMMS in the group receiving treatment with fluoxetine was not significantly improved. This was not as convincing as the widely acclaimed multi-centre FLAME trial which examined 113 participants and detected a positive effect on motor function recovery as adjudged by changes in FMMS. ${ }^{16}$ The difference in the outcomes of both studies could be attributed to the longer duration of observation for participants in the FLAME trial, which was three months as compared to one month in our study.

Considering the correlations between motor function and functional status adjudged by FMMS and BI respectively, it can be interpreted that the trend for benefit shown using FMMS may correlate positively to the significant benefit in functional status using BI. This is logical considering that while the FMMS lays emphasis on the motor function of the paretic side; the Barthel index examines functions that require synergy in the use of both sides. The high case fatality rate is consistent with previous hospital data from the region. This is comparable to the 30-day case fatality rates between 26 and $28 \%$ in Ilorin, Lagos, and Ibadan ${ }^{7,1,3}$. It may improve with better health care strategy and infrastructure including establishment of stroke units, patient education and strengthening of Primary health care.

\section{Limitations}

The small sample population might have affected the sensitivity and generalizability of the study. Secondly, serial assessment of biochemical and haematological parameters could have detected some adverse events that might have been missed. The exclusion of mild and very severe stroke cases meant that the result may not be generalizable for all strokes.

\section{Conclusion}

Fluoxetine, if started early in the acute phase of ischaemic stroke may improve functional status. It also shows a trend for enhancing motor recovery in the paretic side if commenced alongside physiotherapy. Larger studies to better define its benefit in acute stroke may be useful in providing another treatment option in resource poor countries.

\section{Funding details}

No funding or sponsorship was received.

\section{Acknowledgments}

To all the members of the neurology unit who made this work possible, including nurses, physical therapists and dieticians.

\section{Conflicts of interest}

All authors declare no conflicts of interest. 


\section{References}

1. Danesi M, Okubadejo N, Ojini F, et al. Incidence and 30-day case fatality rate of first-ever stroke in urban Nigeria: The prospective community based Epidemiology of Stroke in Lagos (EPISIL) phase II result. J Neurol Sci. 2013;331(1-2):43-47.

2. Ogun SA, Ojini FI, Ogungbo B, et al Stroke in southwest Nigeria: a 10year review. Stroke. 2005;36(6):1120-1122

3. Obiako OR, Oparah SK, Ogunniyi A, et al. Prognosis and outcome of acute stroke in the university college hospital Ibadan, Nigeria. Niger $J$ Clin Pract. 2011;14(3):359-362.

4. National center for health statistics. US 2011. Hyattsvile MD: US department of health and human services, centers for disease control and prevention.

5. Prabhakaran S, McNulty M, O’Neil K, et all ntravenous thrombolysis for stroke increases over time at primary stroke centers. Stroke. 2012;43(3):875-876.

6. State of the nation. Stroke statistics. Stroke assiociation. 2017.

7. Wahab KW. The burden of stroke in Nigeria. Int J Stroke. 2008;3(4): 290-292.

8. Alkali NH, Bwala SA, Akano AO, et al. Stroke, Risk factors, Subtypes and 30 day fatality in Nigeria, Abuja. NigerMed J. 2013;54(2):129-135.
9. Ward NS. Mechanism's underlying recovery of motor function after stroke. Postgrad Med J. 2005;81:510-514.

10. Liepert J. Pharmacotherapy in restorative neurology. Curr Opin Neurol. 2008;28(6):639-643.

11. Rosser N, Floel A. Pharmacological enhancement of motor recovery in sub-acute and chronic stroke. Neurorehabilitation. 2008;23(1):95-103.

12. Berends H, Nijlant J, Movig K, et al. The clinical use of drugs influencing neurotransmitters in the brain to promote motor recovery after stroke: a systematic review. Eur J Phys Rehabil Med. 2009;45(4):621-630.

13. Long D, Young J. Dexamphetamine treatment in stroke. $Q \mathrm{~J}$ Med. 2003;96(9):673-685.

14. Schuster C, Mannz G, Kischka U, et al. Dexamphetamine improves upper extremity outcome during rehabilitation after stroke: apilot randomized controlled trial. Neurorehabil Neural Repair. 2011;25(8):749-755.

15. Scheidmann K, Fries W, Muller F, et al. Effect of Levodopa in combination with physiotherapy on functional motor recovery after stroke: a prospective randomized double blind study. Lancet. 2001;358(9284):787-790.

16. Chollet F, Tardy J, Albucher JF, et al. Fluoxetine for motor recovery after acute ischaemic stroke (FLAME): a randomized controlled trial. Lancet neurol. 2011;10(2):123-130. 